\title{
Impact of Material Deterioration on the Strength of Reinforced Concrete Half Joint Structures
}

\section{Citation:}

P. DESNERCK, J.M. LEES, C. MORLEY (2015) Impact of Material Deterioration on the Strength of Reinforced Concrete Half Joint Structures, IN: Proceedings of the 2015 IABSE Workshop on Safety, Robustness and Condition Assessments of Structures, Helsinki, Finland, p. 8

\section{Additional Information:}

- This conference paper was presented at the 2015 IABSE Workshop on Safety, Robustness and Condition Assessments of Structures, Helsinki, Finland, 11-12 February 2015

Version:

Accepted for publication 


\title{
Impact of Material Deterioration on the Strength of Reinforced Concrete Half-Joint Structures
}

\author{
Pieter DESNERCK \\ Research Associate \\ University of Cambridge \\ Cambridge, UK \\ Pieter.Desnerck@eng.cam.ac.uk
}

\author{
Janet M. LEES \\ Reader in Civil Engineer- \\ ing \\ University of Cambridge \\ Cambridge, UK \\ jml2@eng.cam.ac.uk
}

\author{
Chris MORLEY \\ Emeritus Senior Lecturer in \\ Concrete Structures \\ University of Cambridge \\ Cambridge, UK \\ ctm1@eng.cam.ac.uk
}

\begin{abstract}
Summary
During the 1960's and 1970's a number of reinforced concrete (RC) bridges were constructed with 'half-joints' introduced into bridge decks. A half-joint is a particular type of RC structure that was introduced into bridge decks as a means of simplifying the design and construction operations. However, a major disadvantage is that there are problems associated with leakage of water through the joint leading to concrete deterioration and corrosion of the reinforcement.

When assessing the integrity of existing half-joint structures, determining the influence of material deterioration and/or repair works is a challenge as current code provisions or guidelines do not provide guidance on how to take any associated strength losses into consideration.

This paper focusses on the impact of changes in the material properties (such as compressive strength, yield strength of the reinforcement, reinforcement bar diameter, etc.) on the load bearing capacity of reinforced half-joint structures. The vulnerability of a typical half-joint design to these changes is analysed using finite element models. The results allow designers, assessors and decision makers to better quantify the impact of observed deterioration phenomena on the predicted strength of the studied half-joint.
\end{abstract}

Keywords: assessment, bearing capacity, concrete bridge, corrosion, deterioration, half-joint.

\section{Introduction}

In the UK, existing infrastructure is aging and this has consequences for the safety of tunnels, bridges, dams, etc. [1].

A number of bridges built in the 60's and 70's were designed with half-joints. A half-joint (sometimes referred to as dapped end) is a particular type of RC structure (Figure 1) that was introduced as a means of simplifying design and construction operations. It is a support detail where an Lshaped nib supports an inverted nib of a drop-in span. The advantages of this construction type include a level running surface along the bridge deck and the support spans. In addition, precast beams can be easily lifted into place and supported during construction.

However, leakage through the joint can cause significant problems. For example, chloride rich seepage can cause concrete deterioration and corrosion of the reinforcement near the nib. Loss of part of the reinforcement bar cross-section due to corrosion can induce higher stresses in certain regions of the structural member and significantly reduce the safety margins [2]. TS Interim Amendment No. 20 [2] states: 'Half-joints are a particular concern because they are not easily accessible for inspection or maintenance and they are mostly located over or under live traffic lanes.' 

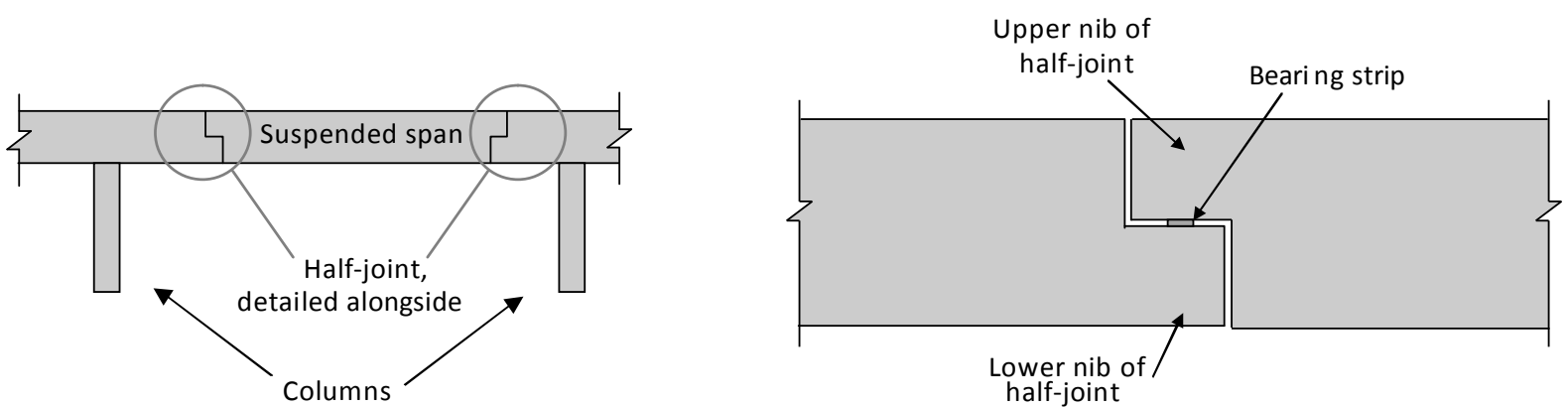

Figure 1: Typical half-joint geometry (based on [1])

After the collapse of the de la Concorde Overpass in Canada and tragic death of five people, the shear resistance of half-joints has come under intense scrutiny. A Commission of Inquiry [3] conducted a thorough investigation and concluded that the overpass was sufficient to carry the applied loads. However, the concrete freeze-thaw resistance was deficient and the detailing did not comply with best practice. The detailing vulnerabilities may have been exacerbated during construction when some reinforcing bars were misplaced. Furthermore, repair interventions, during which regions of concrete were removed and replaced, could also have had a negative impact. This incident shows that the load capacity of half-joint structures can be influenced to a significant extent by improper execution during the construction of a bridge, deterioration processes, repair works, etc.

With respect to bridge assessments, strut-and-tie methods are often used [4] but can be overly conservative. A structure with deteriorated elements may still be serviceable, but there is a distinct lack of validated tools to accurately predict the residual capacity. In the past, a number of experimental studies on half-joint beams have been conducted [5], [6] but those have typically focussed on new construction. Older structures with deteriorated concrete represent an additional challenge. The two main shear failure planes in a half-joint structure are a full slab failure and a failure at the re-entrant corner (Figure 2). But there are complex interactions between these failure modes and they are sensitive to small changes in the detailing and/or strength reductions due to concrete deterioration.

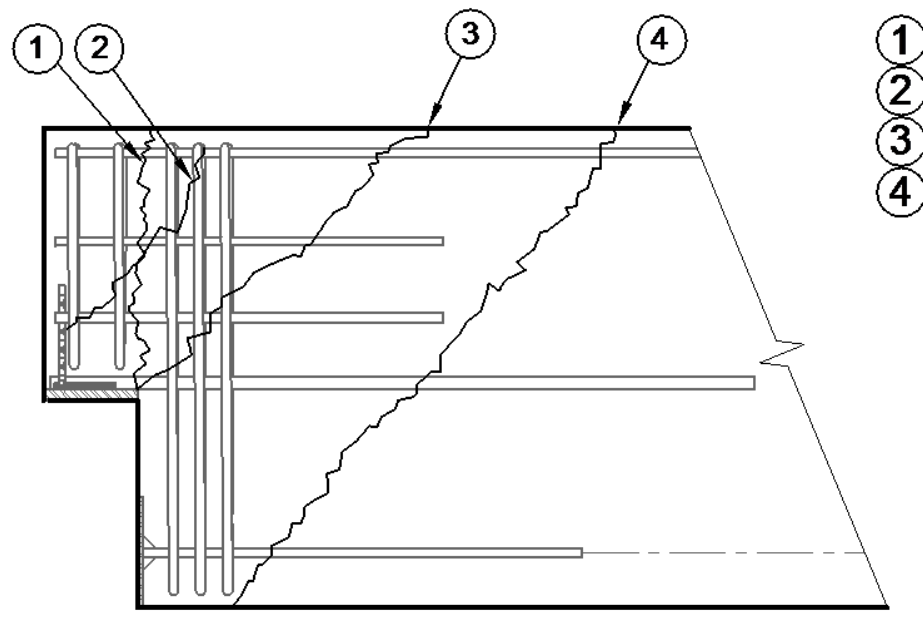

(1) nib shear failure

2) inclined shear failure in nib

(3) crack initiated in corner

(4) shear failure in beam nearby

Figure 2: Potential failure modes in half-joint connections (based on [7])

To quantify the effect of deterioration of a half-joint, a nonlinear finite element (NLFE) model of a typical detail was developed. The properties of the reinforcement and concrete are varied and results analysed with respect to failure load and deformations. 


\section{Simulation Process}

\subsection{Half-joint geometry and reinforcement lay-out}

In order to obtain meaningful results on a representative half-joint detail, a literature review was carried out to identify common dimensions and reinforcement lay-outs. Two major categories of half-joint reinforcement lay-outs were noticed. One group of designs (type A) consisted of a diagonal bar being placed near the nib (bringing the load on the nib back up to the top level of the beam) and the other group (type B) consisted of denser shear reinforcement near the nib often combined with longitudinal reinforcement anchored by anchor plates. Both lay-outs are shown in Figure 3.

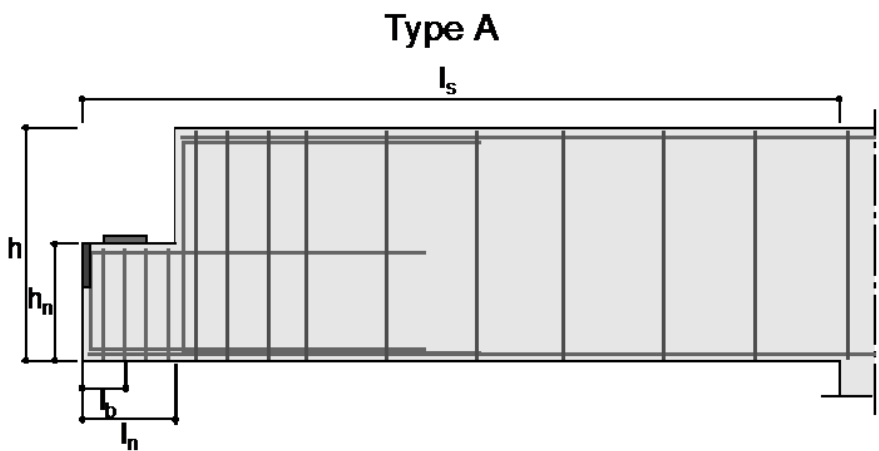

Type B

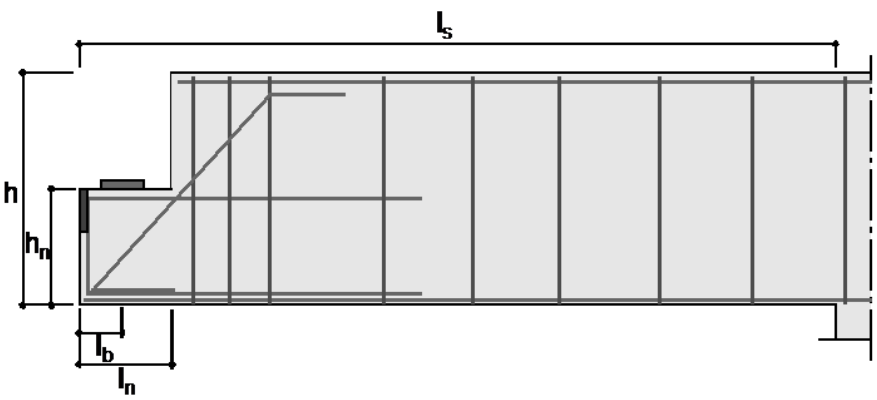

Based on the literature review, a typical half-joint design was developed. A height of $700 \mathrm{~mm}$ was chosen for the dapped end support. The ratio of the nib height to the overall height of the beam for most half-joints is about 0.45 to 0.5 . In the selected design a value of 0.47 was applied.

As most common reinforcement lay-outs in UK bridges are those with a diagonal reinforcing bar in the nib, the selected half-joint was designed based on that approach. The required reinforcement cross-sectional areas were calculated using a simple strut-and-tie model assuming a design load on the dapped end support of $300 \mathrm{kN}$.

Figure 3: Typical reinforcement lay-outs for half-joints

The final geometry of the $400 \mathrm{~mm}$ wide beam is shown in Figure 4 . Table 1 provides information on the applied reinforcement lay-out.

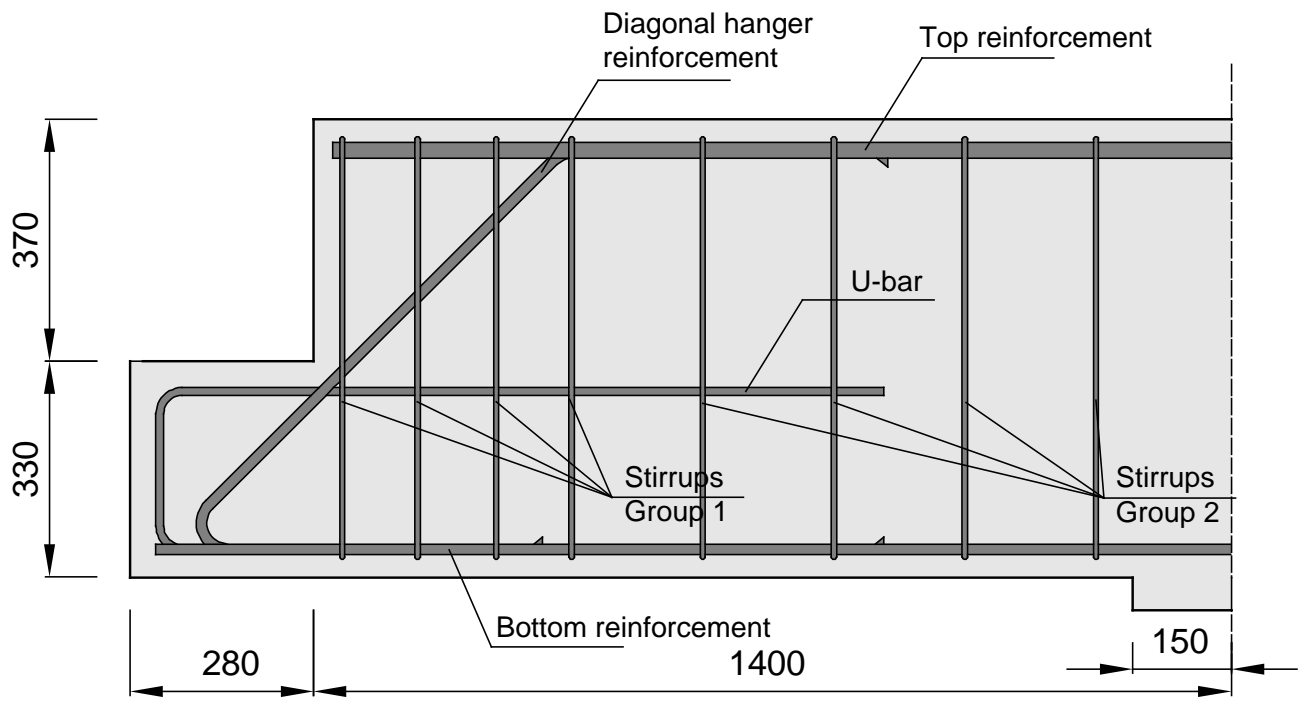

Figure 4: Geometry and reinforcement layout of studied half-joint detail 


\begin{tabular}{lcl}
\hline Reinforcing bars & $\mathbf{A}_{\mathbf{s}}\left[\mathbf{m m}^{2}\right]$ & Lay-out \\
\hline Top reinforcement & 1963 & $4 \times \phi 25 \mathrm{~mm}$ \\
Bottom reinforcement & 603 & $3 \times \phi 16 \mathrm{~mm}$ \\
Diagonal hanger reinforcement & 603 & $3 \times \phi 16 \mathrm{~mm}$ \\
U-bar & 402 & $2 \times \phi 16 \mathrm{~mm}$ \\
Stirrups group 1 & $4 \times 151$ & $4 \times 3 \times \phi 8 \mathrm{~mm}$ \\
Stirrups group 2 & $4 \times 151$ & $4 \times 3 \times \phi 8 \mathrm{~mm}$ \\
\hline
\end{tabular}

\subsection{FE Modelling}

A 2D-model of the half-joint geometry and reinforcement lay-out shown in Figure 4 has been implemented in the finite element program TNO DIANA 9.5 [8]. Eight-noded quadrilateral isoparametric plane stress elements were used for the concrete. These elements are based on quadratic interpolation and Gaussian integration. The reinforcement was modelled as embedded reinforcing bars, adding stiffness to the mother elements in the finite element model. In this modelling approach, full bond between the reinforcing bars and concrete is maintained throughout.

Non-linear finite element analyses were carried out in which a non-linear concrete behaviour in compression as well as in tension was applied. The tensile behaviour of the concrete was modelled by means of a total strain based smeared crack approach with rotating cracks. The compressive behaviour was modelled as a bilinear relationship between stresses and strain. The baseline concrete and steel properties can be found in Table 2.

Table 2: Assumed concrete and steel properties

\begin{tabular}{lcllcl}
\hline & Concrete & & Steel & \\
\hline Young modulus & $\mathrm{E}_{\mathrm{c}}$ & $30.000 \mathrm{MPa}$ & Young modulus & $\mathrm{E}_{\mathrm{s}}$ & $210.000 \mathrm{MPa}$ \\
Poisson ratio & $v$ & 0.2 & Poisson ratio & $v$ & 0.3 \\
Compr. strength & $\mathrm{f}_{\mathrm{c}}$ & $30 \mathrm{MPa}$ & Yield stress & $\mathrm{f}_{\mathrm{y}}$ & $525 \mathrm{MPa}$ \\
Tensile strength & $\mathrm{f}_{\mathrm{ct}}$ & $3 \mathrm{MPa}$ & & & \\
Tensile strain & $\varepsilon_{\mathrm{cu}}$ & 0.0027 & & & \\
\hline
\end{tabular}

\section{Results and discussion}

Due to deterioration processes, the mechanical properties of concrete and steel can alter over the life-time of a reinforced concrete half-joint. The extent to which carbonation, chloride ingress, cracking and other processes affect the compressive strength, tensile strength and modulus of elasticity of the concrete has been discussed in an earlier publication [9].

The largest effect on the bearing capacity is expected to be linked to the corrosion of the reinforcing steel. As half-joints are heavily reinforced it is rather unclear which bars will have the biggest impact on the overall load bearing capacity of the element. Therefore in this study a stepwise approach is applied where an increasing extent of corrosion is modelled for each bar independently, in order to detect the bars that will lead to the most significant load bearing capacity reductions.

In the past, studies have determined the properties of corroded reinforcing bars. Almusallam et al. [10] proved that corroded reinforcing bars do not show significant changes in yield strength when the actual rebar diameter is considered (where the diameter reduces for increasing corrosion). However when the nominal rebar diameter is used (regardless of the actual reduction), a distinct reduction in $\mathrm{f}_{\mathrm{y}}$ can be seen. Results of Apostolopoulos et al. [11] confirm these observations. In this way, the effect of corrosion can be modelled by either reducing the bar diameter $\phi$ or by maintaining $\phi$ and reducing the yield stress of the steel. Hereafter both approaches will be applied. 


\subsection{Influence of reinforcing bar diameters}

\subsubsection{Longitudinal top reinforcement}

As the water proofing layers on concrete bridge decks have a tendency to fail, the top reinforcement is vulnerable to corrosion along its entire length. In order to investigate the effect of a reduction of the steel amount/quality in the top reinforcing layer, NLFE simulations have been performed using the two approaches for modelling corrosion discussed previously. In the first series of analyses the cross-sectional area $A_{s}$ of the top bars was decreased in steps of $10 \%$ up to $50 \%$ of the original value. In a second series, the diameter was kept constant but the yield strength of the bar was decreased in steps of $10 \%$ up to $50 \%$. The impact on the load bearing capacity is shown in Figure 5.

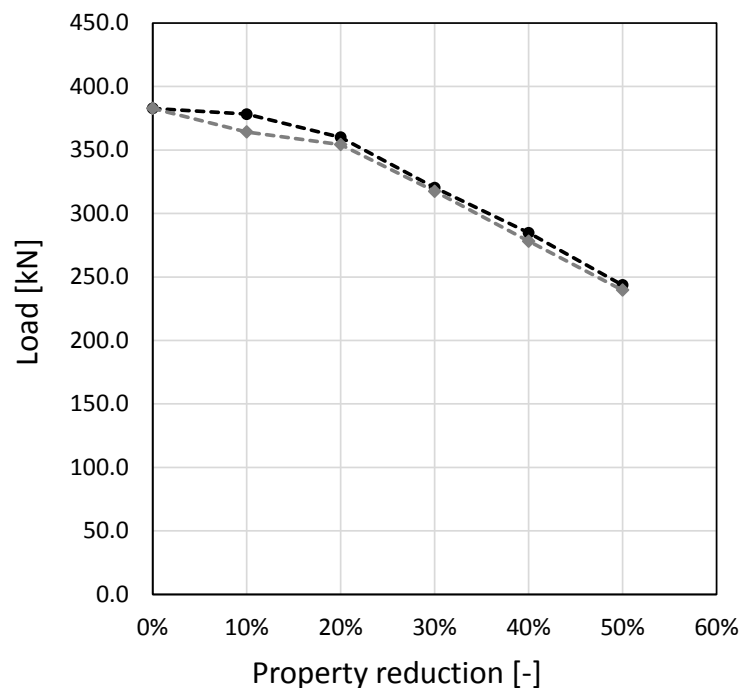

Figure 5: Load bearing capacity as a function of top bar yield strength and $A_{s}$ reduction

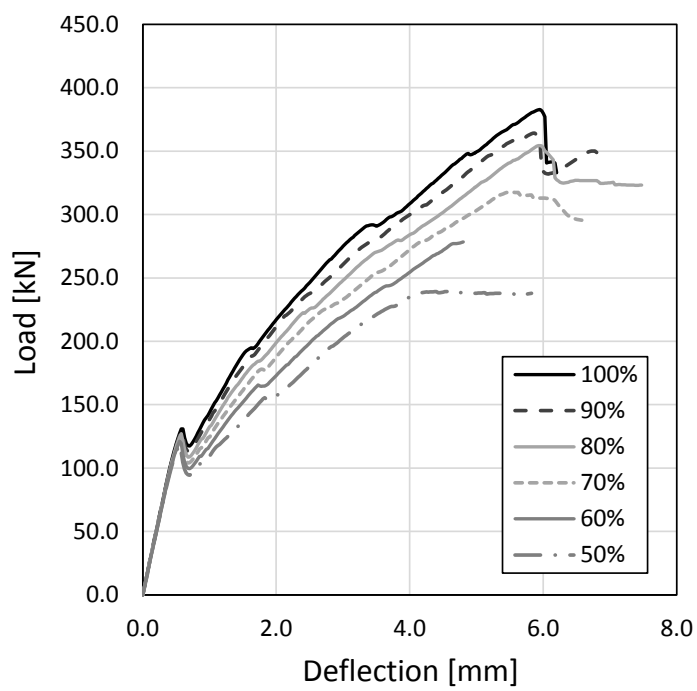

Figure 6: Load-deflection curves as a function of top bar $A_{s}$ reduction

When there is no corrosion, the NLFE prediction for the load bearing capacity of the original design is $383 \mathrm{kN}$, which is significantly above the design load of $300 \mathrm{kN}$, suggesting that strut-and-tie approach used to detail the half-joint has given a satisfactory design and presumably a lower bound on the half-joint capacity. It can be seen that both corrosion modelling approaches give the same trend with respect to the overall decrease in bearing capacity. Slightly higher capacities are obtained with the yield stress reduction approach, but the differences between both methods is smaller than 4\%. As the applied approach does not lead to significant differences in load bearing capacity, hereafter only the decreasing cross-sectional area method will be applied.

Figure 6 shows the load - deflection curves (deflection at the bottom of the nib) for different crosssectional areas of the top reinforcement. In the initial stage of loading the behaviour does not depend on $A_{s}$, whereas after first cracking (load of $120 \mathrm{kN}$ ), the stiffness of the beam is reduced with a lower $A_{s}$. In all cases, the simulations predict that failure is initiated due to the yielding of the top layer of reinforcement at the support. 
Since the dominant failure mode of the studied half-joint is by yielding of the top reinforcement near the support followed by concrete crushing at the bottom, a reduction of the amount of reinforcement in the compressive zone influences the bearing capacity. However, the impact is smaller than that of the tensile reinforcement reduction. A decrease of $50 \%$ in compression reinforcement cross-section leads to a reduction of the failure load of $13 \%$ to a value of $332 \mathrm{kN}$ (see Figure 7).

Overall the decrease is more or less linear with increasing corrosion level and so with decreasing bar diameter.

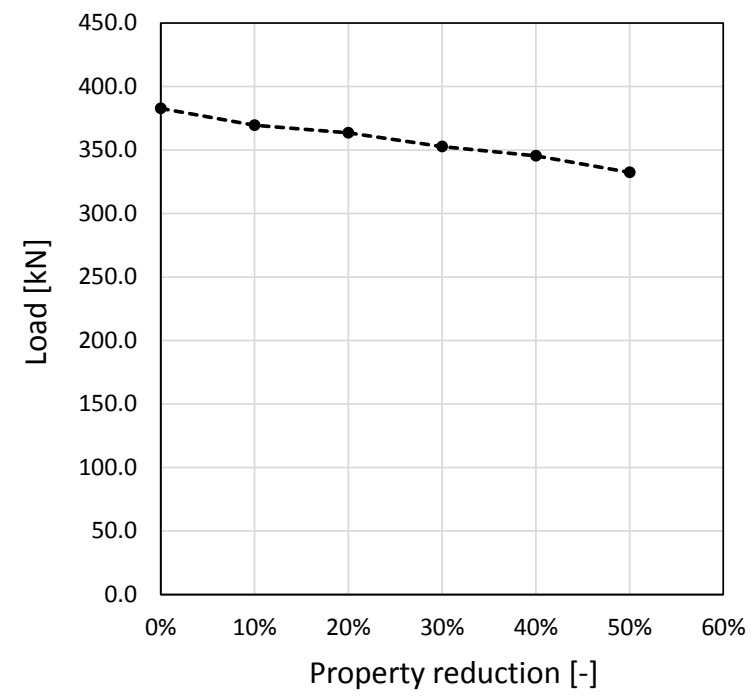

Figure 7: Load bearing capacity as a function of longitudinal bottom bar $A_{s}$ reduction

\subsubsection{Diagonal hanger reinforcement}

A reduction of up to $20 \%$ in the diagonal hanger reinforcement does not lead to an immediate reduction in the load capacity (Figure 8). This is because the dominant failure mode remains as the yielding of the top reinforcement. In addition, as the diagonal bar area reduces there is a redistribution of the forces from the diagonal hanger towards the vertical stirrups and U-bar. Hence a reduction in load capacity is only observed after a $30 \%$ loss of section. The failure mode at this point then shifts from a top-bar yield failure towards a nib shear failure.
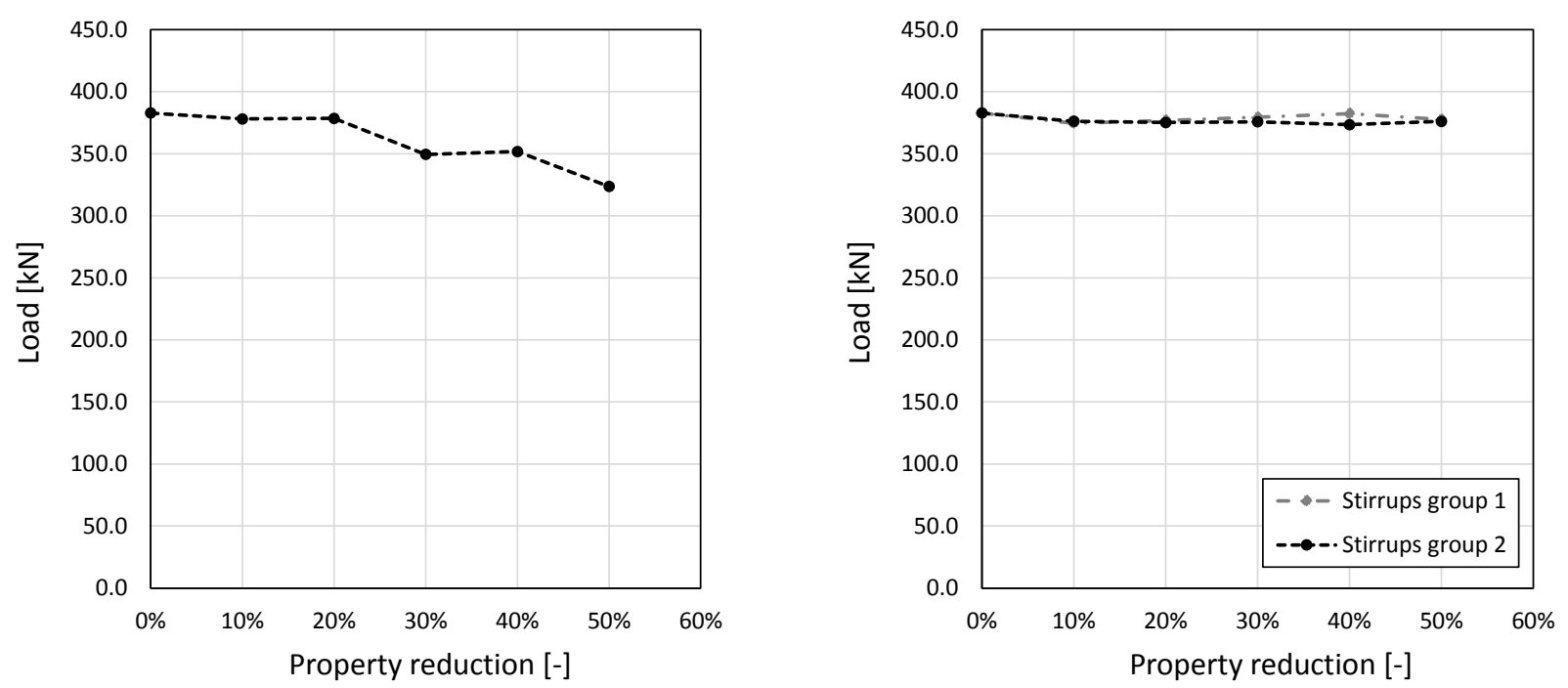

Figure 8: Load bearing capacity as a function of Figure 9: Load bearing capacity as a function of diagonal hanger $A_{s}$ reduction stirrup As reduction

\subsubsection{Shear reinforcement in the beam and near the nib}

The influence of the shear reinforcement was studied by reducing the bar diameters in two separate groups of stirrups. The first group consisted of stirrups 1 to 4 starting from the nib (the vertical reinforcement interacting with the diagonal hanger) and a second group consisting of the shear rein- 
forcement in the bulk part of the beam (stirrups 5 to 8). The FE results indicate that even with a significant reduction of the shear reinforcement the dominant failure mode remains by yielding of the top reinforcement and hence the failure load is not significantly influenced. Even when the stirrup cross-sectional area is reduced by $50 \%$, this still provides sufficient shear reinforcement.

\subsection{Influence of concrete properties}

Earlier studies have taken concrete deterioration into consideration when running non-linear FE analyses. Mitchell at al. [12] reduced the width of the concrete elements in their FE model to simulate a reduced capacity and account for potential cracking. Two sets of simulations have been performed in this study. In the first set the original width of $400 \mathrm{~mm}$ is reduced to $200 \mathrm{~mm}$ in $40 \mathrm{~mm}$ steps while maintaining to original reinforcement lay-out, whereas in the second set the concrete compressive strength $f_{c}$ is decreased to $50 \%$ of its original value. The tensile strength $f_{c t}$ and Young modulus $E_{c}$ have been adjusted accordingly using the relationships given in EuroCode 2 and the actual compressive strength. Figure 10 compares the results from both approaches.

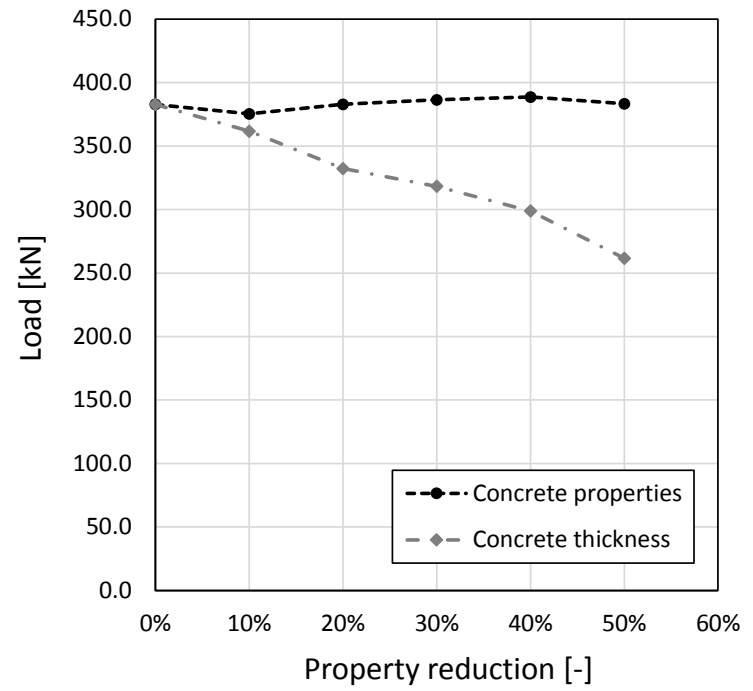

Figure 10: Load bearing capacity as a function of thickness and reduction in concrete properties

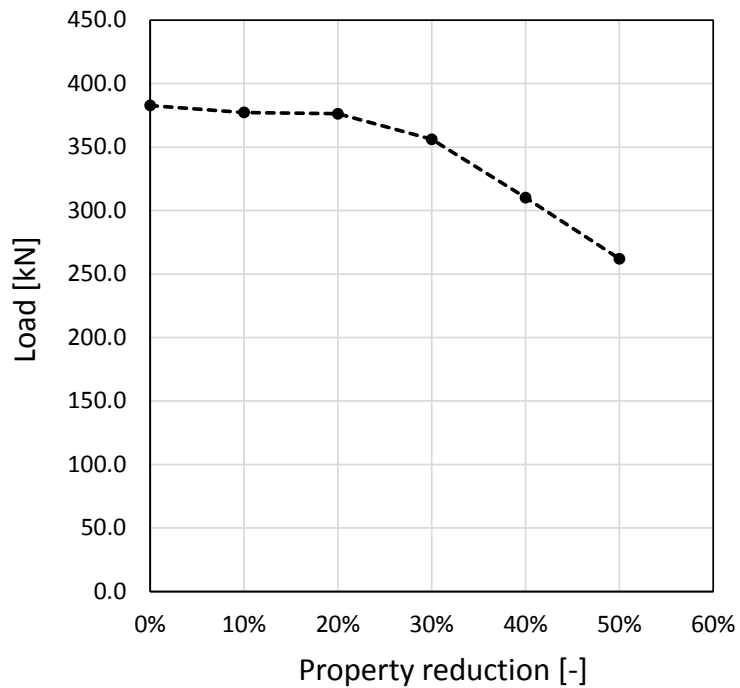

Figure 11: Load bearing capacity as a function of diagonal, $U$-bar and stirrup $A_{s}$ reduction

The decrease in concrete properties does not lead to an as significant decrease in capacity as the reduction of the concrete thickness. Although the stiffness does increase leading to larger deformations, the failure load is only influenced to a minor extent. This observation leads to the conclusion that reducing the concrete width differs significantly from altering the concrete properties and so caution is required when this method is applied.

\subsection{Combined effects}

It was noted in the previous sections that a reduction in the diagonal hanger reinforcement or the vertical shear reinforcement close to the nib does not lead to an immediate reduction in the overall capacity as a redistribution of forces takes place. As any deterioration of a half-joint is likely to primarily affect the reinforcement bar regions close to the re-entrant corner of the nib, a local reduction of the U-bar, diagonal bar and first shear stirrup has been modelled. In this way, the potential for redistribution is limited as all rebars show a reduction in the area with highest steel stresses. The obtained failure loads (Figure 11) show a clear decrease with increasing reduction of the bar diameters. A decrease of $20-30 \%$ can reduce the load carrying capacity to $93 \%$ of the 
original value, whereas decreases of $40 \%$ can lead to a reduction of the load carrying capacity by as much as $19 \%$.

\section{Conclusions}

Half-joints in RC bridges have significant advantages, but are prone to deterioration. Robust guidance on how to assess these structures and interpret visual inspection data is currently not available. Therefore this study tries to identify the effect of corrosion and concrete deterioration for a specific half-joint detail by means of non-linear finite element modelling. The results show that:

- Rebar corrosion can be modelled by reducing the bar diameter or reducing the yield strength. Both methods tend to give similar results.

- Structures failing by yielding of the top reinforcement are most affected by a reduction in the cross-sectional area of this top reinforcement.

- Reducing the cross-sectional area of reinforcing bars near the nib can result in a redistribution of forces resulting in a minor impact on the overall load carrying capacity. However, the combined effect of locally reducing several bars at once (in regions most affected by deterioration) can significantly impact the overall behaviour.

- Simulating the effect of concrete deterioration by means of reducing the width of the concrete section tends to have a higher impact on the results than reducing the concrete properties $\left(f_{c}, f_{c t}\right.$ and $\left.E_{c}\right)$ for the detail studied in the current work.

\section{References}

[1] BELL B. and LOUDON Loudon, "FRP strengthening of concrete road and rail bridges in the UK" Mag. Concr. Res., vol. 62, no. 4, pp. 243-252, Jan. 2010.

[2] TRANSPORT SCOTLAND, "TS Interim Amendment No. 20 - Concrete half-joint deck structures." Agency of the Scottish Executive, p. 23, 2006.

[3] JOHNSON P., COUTURE A. and NICOLET R., "Commission of inquiry into the collapse of a portion of the de la Concorde overpass - Report," 2007.

[4] DEPARTMENT OF TRANSPORTATION, "Design manual for roads and bridges - Vol. 3 Highway structures: Inspection and maintenance - Section 4: Assessment - Part 6 BA39/93 Assessment of Reinforced Concrete Half-joints. ” Department of Transportation, p. 22, 1993.

[5] NANNI A. and HUANG P., "Validation of an alternative reinforcing detail for the dapped ends of prestressed double tees." PCI J., vol. 47, no. 1, pp. 38-49, 2002.

[6] CLARK L. and THOROGOOD P., "Serviceability behaviour of reinforced concrete half joints," Struct. Eng., vol. 66, no. 18, pp. 295-302, 1988.

[7] PRESTRESSED CONCRETE INSTITUTE, PCI Design Handbook, 7th ed. Precast/Prestressed Concrete Institute, 2007, p. 786.

[8] TNO DIANA BV, "TNO Diana 9.5." Delft, the Netherlands, 2014.

[9] DESNERCK P., LEES J. and MORLEY C., "Assessment of reinforced concrete half-joint structures: dealing with deterioration," in Proceedings of the 2014 PCI Convention and National Bridge Conference, 2014, p. 16.

[10] ALMUSALLAM A., "Effect of degree of corrosion on the properties of reinforcing steel bars," Constr. Build. Mater., vol. 15, no. 8, pp. 361-368, Dec. 2001.

[11] APOSTOLOPOULOS C., PAPADOPOULOS M., and PANTELAKIS S., "Tensile behavior of corroded reinforcing steel bars BSt 500s," Constr. Build. Mater., vol. 20, no. 9, pp. 782789, Nov. 2006.

[12] MITCHELL D. and COOK W., "Rapport sur les causes techniques de l'effondrement du viaduc de la Concorde - Annexe A9 - Analyse non-linéaire du porte-à-faux du viaduc de la Concorde," 2007. 